\title{
IMPLICAÇÕES NO PROCESSO EDUCATIVO DAS CRIANÇAS \\ DECORRENTES DA MIGRAÇÃO COMPULSÓRIA DO ENSINO \\ PRESENCIAL PARA O ENSINO REMOTO EM UMA ESCOLA DE \\ MACAPÁ/AP
}

Izaias Loureiro Tavares'

Eliana do Socorro de Brito Paixão²

\section{RESUMO}

O presente artigo tem por objetivo analisar as implicações da migração compulsória do ensino presencial para o ensino remoto na perspectiva de docentes alfabetizadores de uma unidade escolar do município de Macapá, capital do Estado do Amapá, que se deu a partir da pandemia de COVID-19 no ano de 2020 e permanece no ano de 2021. Este estudo é de abordagem qualitativa que se constitui a partir de uma pesquisa explicativa no âmbito da análise do conteúdo das respostas obtidas em questionário online aplicado aos docentes alfabetizadores de uma escola da rede pública municipal de Macapá/AP. Como resultado, observou-se que os docentes, em geral, se sentiram frustrados após receberem a determinação para ministrar as suas aulas remotamente, tendo em vista que apesar de receberem relativo treinamento e capacitação para ministração de suas aulas em um novo formato, os alunos e o sistema acabam por não favorecer o processo de ensino remoto em uma área periférica, por exemplo, onde grande parte dos responsáveis e alunos não possuem acesso à internet, outros nem aparelho celular tem, fazendo com que a alfabetização, etapa importante da escolarização, reste prejudicada.

Palavras-chave: Ensino Remoto. Tecnologias Educacionais. Práticas Pedagógicas.

\footnotetext{
1 Especialista em Docência do Ensino Superior pela Faculdade META; Docente efetivo da Universidade do Estado do Amapá (UEAP) - Macapá - Amapá - Brasil; Mestrando do Programa de Pós-Graduação em Educação da Universidade Federal do Amapá (PPGED/UNIFAP); Membro do Grupo de Estudos e Pesquisas em Estatística e Matemática do Amapá - GEPEMA. Orcid iD: https://orcid.org/0000-0001-5578-4314. E-mail: izaias.tavares@veap.edu.br

2 Doutora em Educação pela Universidade Federal de Uberlândia (UFU); Docente efetiva da Universidade Federal do Amapá (UNIFAP) - Macapá - Amapá - Brasil; Docente Permanente do Programa de Pós-Graduação em Educação da Universidade Federal do Amapá (PPGED/UNIFAP); Membro do Grupo de Pesquisa Arquitetura e Urbanismo na Amazônia GAU. Orcid iD: https://orcid.org/0000-0002-7978-1836. E-mail: elianapaixao@unifap.br
} 


\title{
IMPLICATIONS IN THE EDUCATIONAL PROCESS OF CHILDREN RESULTING FROM \\ THE COMPULSORY MIGRATION FROM CLASSROOM TEACHING TO REMOTE \\ TEACHING IN A SCHOOL IN MACAPÁ/AP
}

\begin{abstract}
This article aims to analyze the implications of the compulsory migration from on-site education to remote education from the perspective of literacy teachers at a school unit in the city of Macapá, capital of the State of Amapá, which occurred after the COVID-19 pandemic in the year 2020 and remains in the year 2021. This study has a qualitative approach that is based on an explanatory research within the scope of the analysis of the content of the responses obtained in an online questionnaire applied to literacy teachers of a public municipal school in Macapá/AP. As a result, it was observed that teachers, in general, felt frustrated after receiving the determination to teach their classes remotely, considering that despite receiving relative training and qualification to teach their classes in a new format, the students and the system ends up not favoring the remote teaching process in a peripheral area, for example, where most parents and students do not have access to the internet, others do not even have a cell phone, making literacy, an important stage of schooling, remains impaired.
\end{abstract}

Keywords: Remote Learning. Educational Technologies. Pedagogical Practices.

IMPLICACIONES EN EL PROCESO EDUCATIVO DE LOS NIÑOS RESULTANTES DE LA MIGRACIÓN OBLIGATORIA DE LA EDUCACIÓN PRESENCIAL A LA EDUCACIÓN

A DISTANCIA EN UNA ESCUELA DE MACAPÁ/AP

\section{RESUMEN}

Este artículo tiene como objetivo analizar las implicaciones de la migración obligatoria de la educación presencial a la educación remota desde la perspectiva de los alfabetizadores de una unidad escolar de la ciudad de Macapá, capital del estado de Amapá, ocurrida luego de la pandemia de COVID-19. en el año 2020 y permanece en el año 2021. Este estudio tiene un enfoque cualitativo que se basa en una investigación explicativa en el ámbito del análisis del contenido de las respuestas obtenidas en un cuestionario en línea aplicado a alfabetizadores de un colegio público municipal en Macapa / AP. Como resultado, se observó que los docentes, en general, se sintieron frustrados luego de recibir la determinación de impartir sus clases de forma remota, considerando que a pesar de recibir relativa capacitación y calificación para impartir sus clases en un nuevo formato, los estudiantes y el sistema no termina favoreciendo el proceso de enseñanza a distancia en un área periférica, por ejemplo, donde la mayoría de los padres y estudiantes no tienen acceso a internet, otros ni siquiera tienen un teléfono celular, lo que hace que la alfabetización, una etapa importante de la escolarización, permanezca comprometida.

Palabras clave: Aprendizaje a Distancia. Tecnologías Educativas. Prácticas Pedagógicas. 


\section{INTRODUÇÃO}

Novos arranjos educacionais vêm sendo disseminados em todos os sistemas de ensino em decorrência do cenário pandêmico vigente, que nunca dantes fora experimentado. A disseminação rápida de um novo coronavírus denominado SARS-Cov-2, causador da doença COVID-19, ocasionou uma crise sem precedentes recentes aos docentes, discentes e gestores que tentam com louvável esforço e normalmente sem apoio dos sistemas de ensino, mitigar os efeitos nefastos na educação escolar. Nesse contexto, Saviani (2020 p. 05) pondera que:

Enquanto a classe dominante tende a encarar as crises como simples disfunções que apenas exigem rearranjos (reformas), a classe dominada tenderá a encarar as crises conjunturais como expressão das contradições de estrutura, buscando explorar a crise de conjuntura para mudar a correlação de forças tendo em vista a transformação estrutural da sociedade.

No enfrentamento desta crise, sob a justificativa de não incorrer em solução de continuidade, a maioria dos sistemas de ensino se reorganizou alternativamente, diante da persistência do cenário pandêmico e de isolamento social, que fez com que prédios escolares no mundo todo fossem literalmente fechados em 2020 para proteger alunos e professores da propagação da doença.

Assim, a presente pesquisa objetiva analisar quais as implicações da migração compulsória do ensino presencial para o ensino remoto na perspectiva de docentes alfabetizadores que se deu a partir da pandemia de COVID-19 no ano de 2020 e permanece no ano de 2021? Tem como locus uma unidade escolar do município de Macapá, capital do Estado do Amapá. O estudo fundamenta-se em uma abordagem qualitativa que se constitui a partir de uma pesquisa explicativa. Os dados são interpretados no âmbito da análise do conteúdo, por meio das respostas obtidas em questionário online aplicado aos docentes alfabetizadores de uma escola da rede pública municipal de Macapá/AP. 
Observou-se que a alternativa encontrada, em vários locais, foi direcionar o aprendizado para o ensino à distância (com as devidas particularidades que a modalidade impõe), em outros lugares a solução fora - Ensino Remoto Emergencial (ERE) - encarado por muitos como uma transposição da educação presencial para ambientes virtuais ou com a interação remota realizada documentalmente, e outros adotaram o Ensino Híbrido (blended learning), com parte da carga horária sendo cumprida de forma presencial e parte a distância.

O estudo discute ao longo de duas seções neste artigo os reflexos da pandemia e o ensino remoto, bem como a migração compulsória do ensino presencial para o ensino remoto no Município de Macapá/AP, com o objetivo de contribuir para uma compreensão desse processo de ensino em tempos de pandemia na formação das crianças no âmbito de uma unidade escolar do sistema de ensino pesquisado.

\section{OS REFLEXOS DA PANDEMIA NA EDUCAÇÃO E O ENSINO REMOTO EM MACAPÁ/AP}

A mudança na organização da educação, devido a necessidade de isolamento social imposto como medida para evitarmos a transmissão do vírus da Covid 19, colocou professores, alunos e seus pais em uma nova situação em relação à escolarização. Mais de um ano se passou desde o início desta pandemia, e ainda é muito cedo para avaliar o impacto efetivo da COVID-19 na educação. A todo momento vários estudos estão sendo realizados e publicados considerando experiências locais, regionais e alguns poucos de abrangência nacional ou internacional, justamente por conta da dificuldade em o fazê-lo.

Como exemplo, tem-se Cullinane e Montacute (2021) que confirmaram a disponibilidade de equipamentos tecnológicos nas residências dos alunos como uma grande preocupação na transição para o ensino à distância, e que a desigualdade econômica no lar prejudicava a capacidade destes de participarem efetivamente dos estudos. Ambas as 
ponderações são relevantes ao considerar o cenário amazônico, tendo em vista a limitação operacional dos links de acesso públicos e privados ${ }^{3}$ em comparação com as demais regiões do Brasil, que é o reflexo da capacidade reduzida de acesso dos residentes nesta região, alinhada com sua baixa capacidade econômica.

Além das pesquisas em educação a distância relacionadas à existência de tecnologia, as pesquisas da COVID-19 na área de educação também têm se voltado para a preparação de professores para o ensino a distância. Em vários locais iniciativas de formação emergencial surgem a todo momento. Revistas publicam dossiês temáticos, e em sua grande maioria concluem que grande parte dos professores não tiveram experiência anterior de ensino online, tendo participado de no máximo uma disciplina na graduação ou cursos genéricos de formação continuada na área de informática educativa.

Nesse contexto, se espera que o trabalhador seja capaz de exercer várias funções diferentes (ser polivalente, multifuncional) e que possa adaptar-se às mudanças do mundo do trabalho a fim de garantir sua empregabilidade (ser flexível). Para isso, faz-se necessária uma formação geral que sirva de base para o desenvolvimento dos encargos exigidos nessa nova fase do capitalismo. Assim se exige que a educação tenha por função habilitar pessoas para competir no mercado de trabalho, ampliando suas condições de empregabilidade por meio de cursos diversos. É o indivíduo quem assume a responsabilidade, e também a culpa, pela sua não inserção no mercado de trabalho.

Durante seu processo formativo, o professor aprende que tem o dever de ministrar suas aulas, de realizar sua tarefa docente com zelo e dedicação. Contudo, precisa de condições favoráveis, higiênicas, espaciais, estéticas, sem as quais se move menos eficazmente no espaço pedagógico, e por vezes as condições são tão perversas que não possibilitam nenhum

\footnotetext{
$3 \quad$ Ver RNP em: https://www.rnp.br/sistema-rnp/rede-ipe e CETIC.br https://cetic.br/media/docs/publicacoes/2/20210714181001/tic_provedores_2020_livro_eletr onico.pdf
} 
movimento docente. Segundo Freire (1996), o desrespeito a este espaço é uma ofensa aos educandos, aos educadores e à prática pedagógica.

A partir de Shulman (1987), tem-se que a base para as decisões relacionadas ao ensino dos professores reside em seu conhecimento profissional, que é dividido em conhecimento do conteúdo (conhecimento específico do professor), conhecimento pedagógico do conteúdo (compreensão de como ensinar um tópico específico da disciplina para os alunos) e conhecimento pedagógico geral (conhecimento sobre alunos e aprendizagem, princípios de gestão de sala de aula e objetivos educacionais em geral).

De maneira geral, a questão mais difícil para os professores no uso das ferramentas digitais para apoiar a aprendizagem é a comunicação com os alunos durante o período de ensino a distância e suas variações, para quando esse período passar. Nessa direção, é importante descobrir que a transição para a educação remota em decorrência da COVID-19 influenciou os processos educativos e as respectivas tomadas de decisão dos professores e como eles as justificam no âmbito de suas atividades no sistema municipal de Macapá/AP, cuja unidade escolar objeto deste estudo faz parte.

Observando mais atentamente o caso concreto, ainda há espaço para interpolar os achados com uma discussão específica e interpenetrada entre Infância, Tecnologia e Alfabetização, considerando o cenário amazônico, a partir de estudos e práticas que levam em conta as perspectivas dos professores e do seu trabalho na rede pública de ensino de Macapá, indo para além, para além da formação individual docente, e analisando o caso concreto em confrontação com outras experiências exitosas (ou não), que possam discutir melhor e compreender os principais limites e possibilidades do ensino remoto no contexto pandêmico, para refletir sobre possíveis soluções a serem aplicadas conforme o caso que, no recorte desta pesquisa, se restringiu aos docentes alfabetizadores, do $1^{\circ}$ ao 
$5^{\circ}$ ano do Ensino Fundamental de uma unidade escolar da rede pública municipal de Macapá.

A tecnologia está mudando o processo de alfabetização, à medida que celulares, tablets e computadores antecipam o contato dos pequenos com o alfabeto, com as palavras e, por conseguinte, com processos avançados de letramento digital. Mesmo considerando este como um resultado da ação de ensinar ou de aprender a ler e escrever (SOARES, 2012), a questão aqui, a partir de Freire (1995, p. 11) é que "a leitura de mundo precede a leitura da palavra, daí que a posterior leitura desta não possa prescindir da continuidade da leitura daquele".

E a leitura de mundo que as crianças estão fazendo já é digital, evidenciada no acesso irrestrito a internet e ao consumo muitas vezes não supervisionado de conteúdo, que inevitavelmente causa cenários controversos na infância, como pequenos usuários de internet que não escrevem, não gostam de grafar, mas já estão em nível alfabético. Ou que usam comandos de voz no celular para conseguir assistir a vídeos, para não demonstrar sua limitação escrita, causada pelo desequilíbrio de vivências analógicas e digitais.

O cenário contemporâneo de excessivo o uso de tecnologias, que já impactava os processos consolidados de letramento e alfabetização realizados em regime presencial tiveram seus efeitos catalisados diante do cenário pandêmico, haja vista a migração para as interações mediadas virtualmente, ocasionada pelas restrições de convívio social impostas.

Dessa forma, a alfabetização e letramento precisam estar antenadas e contextualizadas ao cenário altamente tecnológico do contexto contemporâneo, tendo em vista que essas vivências materializam a forma como hoje a criança vive o(no) mundo e (re)aprende a ler o mesmo com lentes distintas (incluindo as digitais), assim buscando uma forma que faça sentido e que promova a superação de desafios que o período apresenta.

Lucon e Zibetti (2020) ponderam que nos primórdios da discussão sobre alfabetização, a busca era sobre qual o melhor método para ensinar, posto 
que se entendia que o fracasso escolar na alfabetização estava relacionado às metodologias inadequadas. No contexto atual, a discussão centra-se sobre tecnologia na educação como facilitadora na aquisição do SEA (Sistema de Escrita Alfabética), considerando aspectos do computador (e hoje o celular) como um suporte de escrita multimodal.

Observando o cenário até agora posto, e considerando a natureza do nível de atendimento da rede municipal (educação infantil e ensino fundamental), em primeiro momento a retomada das atividades pareceu impossível, seja por meio de materiais pedagógicos impressos ou mediado por tecnologias, quando se acatou a suspensão primária por 15 (quinze) dias, a partir de medidas para o enfrentamento da emergência de saúde pública de importância internacional decorrente da pandemia ocasionada pelo coronavírus.

Esta primeira suspensão de atividade letiva da rede municipal de ensino pública e privada ocorreu pelo período de 15 (quinze) dias a contar do dia 18/03/2020 a 01/04/2020 e foi sendo renovada paulatinamente, por meio de novas portarias e decretos. Ficou determinado por ato de ofício do agente mantenedor municipal, que durante os 15 dias de suspensão das aulas (e todas as prorrogações que vieram sucessivamente), o funcionamento das atividades administrativas nas escolas e na SEMED se dariam por meio de teletrabalho, assim considerados aqueles realizados fora das dependências da secretaria e das escolas, com a utilização de tecnologias de informação e de comunicação.

Pensava-se, em primeiro momento, que seria uma suspensão de apenas 15 (quinze) dias, e deixou-se as medidas de reorganização do calendário escolar de 2020 previstas e direcionadas pela Coordenadoria de Gestão Pedagógica da rede municipal. Dessa forma, garantiu-se que não haveria prejuízo de remuneração aos profissionais da educação que estariam ausentes das unidades escolares durante o período de suspensão das aulas e que a frequência dos profissionais da educação, os gestores 
escolares/chefes imediatos deveriam dispensar assinatura no período de suspensão das aulas, fazendo alusão aos decretos normativos.

Saviani (2020) pontua que está evidenciado que as condições mínimas para o ensino remoto funcionar como 'substituto' do ensino presencial não são preenchidas para a grande maioria dos alunos e boa parte dos professores, mas que as redes públicas de ensino e instituições de ensino superior vêm lançando mão do ensino remoto para cumprir o calendário escolar, apenas.

E assim, cumpria-se o primeiro encaminhamento dado, o qual foi prorrogado diversas vezes, até a publicação efetiva da Portaria $n^{\circ}$. 182/2020 - SEMED/PMM, de 04 de maio de 2020, que trouxe em seu bojo as primeiras orientações do que se chamou, no sistema de ensino observado, de atividades letivas não-presenciais, concretizando a migração compulsória de práticas pedagógicas tradicionalmente realizadas em ambientes presenciais para contextos virtualizados e/ou não presenciais.

Neste novo regramento, além de todos os protocolos de segurança e teletrabalho que o cenário exigia, considerou-se as novas orientações Conselho Municipal de Educação de Macapá, que estabeleceram normas específicas quanto à reorganização do calendário escolar para o ano letivo 2020, em decorrência das medidas de enfrentamento à disseminação da pandemia da COVID-19, a partir do disposto no Parecer $n^{\circ}$ 05/2020 do Conselho Nacional de Educação ${ }^{4}$ que estabelece a reorganização do Calendário Escolar e da possibilidade de cômputo de atividades não presenciais para fins de cumprimento da carga horária mínima anual, em razão da pandemia.

Então, nas novas orientações, já se considerava a possibilidade de possíveis prorrogações (o que de fato, ocorreram) mas os encaminhamentos dados para o funcionamento do Setor Pedagógico da SEMED e das escolas já descreviam como deveria ocorrer a implementação de atividades educacionais não presenciais, a partir das orientações específicas da

\footnotetext{
${ }^{4}$ Ver http://portal.mec.gov.br
} 
Coordenadoria de Gestão Pedagógica, seus departamentos e divisões, responsáveis pelo planejamento, acompanhamento, execução e avaliação das atividades educacionais não presenciais nas unidades escolares, definindo que estas deveriam ocorrer de forma não presenciais para todos os alunos da rede pública de ensino.

A metodologia não presencial proposta pressupunha o planejamento integrado da equipe da SEMED com as equipes das unidades escolares, quanto da realização de atividades pedagógicas complementares para o fortalecimento do processo de aprendizagem (e não apenas recomposição de carga horária), utilizando as atividades à distância, que se dariam por meio de atividades pedagógicas não presenciais em diversos suportes. Foi previsto, também, que o agente mantenedor garantiria junto às equipes pedagógicas das unidades a implementação de um sistema contínuo de atividades pedagógicas não presenciais para os educandos, construindo um processo inovador e facilitador do desenvolvimento da aprendizagem.

Para os docentes, seriam providenciadas formações online, a fim de que estes tivessem condições de encaminhar atividades online e offline para os estudantes. E que estas atividades seriam implementadas em regime de teletrabalho ou da impossibilidade de acesso aos meios tecnológicos, deveriam agendar horário diferenciado nas unidades de ensino, evitando, sempre, aglomerações.

Por fim, no anexo do texto da portaria em análise, continham as primeiras orientações para atividades pedagógicas não presenciais durante o período da pandemia da COVID-19, cuja validade iniciava no mês de maio e se estendeu até o fim do ano letivo de 2020, visto que não houve o retorno efetivo presencial em nenhum momento do ano, embora o mesmo tivesse sido anunciado em mais de uma oportunidade.

As orientações dispostas tinham por único objetivo regulamentar as atividades pedagógicas não presenciais durante o período da pandemia da COVID-19 aos estudantes da rede municipal de ensino, para garantir o aproveitamento da carga horária no cômputo das 800 (oitocentas) horas, 
previstas pela legislação Educacional, visto que em todas as normativas os vencimentos dos docentes não foram suspensos. Então houve um movimento nos órgãos de controle para exigir dos servidores públicos resultados compatíveis aos vencimentos recebidos.

Os docentes deveriam lançar as atividades no sistema/plataforma "Escola Com Você", com os conteúdos diários em conformidade com a organização curricular de distribuição de carga horária dos componentes correspondentes ao ano letivo regular e também, o planejamento do professor organizado com a coordenação pedagógica para a recomposição da carga horária, sendo os registros das aulas, carga horária e frequência a partir do dia 4 de maio, lançados na disciplina correspondente ao conteúdo, no diário de classe já utilizado pelo professor antes do primeiro decreto.

Houve nesse ínterim um aumento das atividades semanais para os alunos exercitarem, que foram lançadas no ambiente de controle da secretaria como atividades não presenciais, antes chamadas de atividades complementares, e a quantidade de carga horária a ser lançada seria de quatro horas diárias, que corresponderiam a cinco horas-aula por dia com módulo de 50 minutos cada.

Ficou determinado que as devolutivas das atividades deveriam ser realizadas a qualquer momento, sendo facultado à escola definir a oferta do instrumento de resposta e feedback, podendo utilizar os meios "Escola com Você", via aplicativo WhatsApp® (documento, vídeos ou fotos) ou entregues na escola com prévio agendamento, considerando os cuidados necessários para evitar grandes aglomerações quando for feita na própria escola. Foi determinado também, que o aluno teria acesso ao instrumento disponibilizado sempre que houvesse necessidade, porém o professor deverá providenciar, semanalmente para o aluno e família um guia de orientações com planejamento da execução das rotinas de atividades não presenciais.

No que se refere a Educação Especial, foi determinado que as unidades escolares adotariam medidas de acessibilidade, igualmente 
garantidas enquanto perdurar a suspensão das aulas presenciais e que o professor do Atendimento Educacional Especializado deveria prover atividades com rotinas semanais, fornecendo orientações específicas às famílias e apoios necessários, visto que as atividades deveriam ser articuladas com a coordenação pedagógica e o professor regente da turma com adequações necessárias de materiais.

A primeira ponderação de suporte também surgiu nessa normativa, onde foi previsto que caso o docente tenha dificuldades de acesso à tecnologia ou não tenha disponível, as escolas deveriam disponibilizar acesso às ferramentas necessárias para o envio das aulas, assim como, viabilizar materiais didáticos pedagógicos dentro das possibilidades, para a elaboração das atividades e o docente deveria agendar um horário de ida à escola para fazer uso dos recursos necessários às atividades.

Uma nova função para o pedagogo também foi encontrada em meio ao caos, pois fora determinado que o coordenador deveria auxiliar 0 professor com a turma que apresentasse dificuldades de acesso às tecnologias digitais, assim como, sugerindo outros canais de comunicação, evitando o prejuízo pedagógico aos alunos. Sendo também compelido a este profissional o acompanhamento das atividades lançadas pelo professor, mapeando juntamente com ele, os alunos que não estão realizando as atividades.

Nas orientações gerais, ficou determinado que as atividades pedagógicas não presenciais poderiam acontecer por meios digitais com videoaulas, conteúdos organizados em plataformas virtuais de ensino e aprendizagem, redes sociais, correio eletrônico e blogs. Também por meio de material didático impresso com orientações pedagógicas, livro didático e orientações de leituras de apoio. Para os alunos que não dispunham de acesso ou não dominam as ferramentas digitais, as escolas deveriam prover atividades impressas.

Os conteúdos trabalhados poderiam ainda ser explorados em diversas metodologias para além das listadas, com a realização de atividades 
pedagógicas de estímulo às crianças por meio de leitura de textos pelos pais; desenhos e brincadeiras; jogos e músicas de criança; filmes e programas infantis pela TV; atividades em meios digitais quando possível; revistas digitais, livros didáticos, livros literários e caderno de atividades para os pais desenvolverem com as crianças.

Nas escolas do campo os alunos deveriam ter acesso às atividades por meio de cadernos impressos, livros didáticos, atividades orientadas com guias e orientações aos responsáveis e os monitoramentos destas escolas foram por meio de relatório encaminhado à Divisão do Campo, contendo as mesmas orientações estipuladas para as escolas da zona urbana, mas devendo criar estratégias condizentes com as peculiaridades de cada localidade.

O que se viu, nesse cenário, é que antes de se fazer qualquer proposta, é preciso descobrir quais foram as respostas físicas e culturais a essas adequações impostas pelo sistema. Por essa razão, a oitiva dos agentes educacionais envolvidos diretamente e na linha de frente de atuação das orientações emanadas pelo agente mantenedor do sistema municipal de ensino de Macapá/AP é essencial para testar a eficácia, eficiência e efetividade do modelo adotado a partir das experiências dos docentes que, por conseguinte, acabaram por espelhar práticas e experiências.

\section{A MIGRAÇÃO COMPULSÓRIA DO ENSINO PRESENCIAL PARA O ENSINO REMOTO NO CASO CONCRETO}

Corradini e Mizukami (2016) assentem que o professor é desafiado, por meio de novos paradigmas, a reconstruir suas competências em outras relações interativas no processo de ensino-aprendizagem, ultrapassando a visão restrita da sala de aula e mudando seu perfil de atuação. Assim, ao analisar as implicações decorrentes da migração compulsória do ensino presencial para o ensino remoto na perspectiva de docentes alfabetizadores de uma unidade escolar do município de Macapá, capital do Estado do 
Amapá, essa articulação disruptiva é necessária, a partir de um prisma do materialismo histórico-dialético.

A perspectiva adotada serve para pensar elementos da realidade objetiva da pandemia da COVID-19 e seus reflexos no processo educacional, e as mudanças inerentes à piora do cenário pandêmico considerando a realidade da Amazônia amapaense. No materialismo histórico-dialético há a prioridade do objeto - do real, sobre o sujeito - o ideal; aquele impõe a este que para conhecê-lo, o sujeito transforme a realidade objetiva - o concreto, em concreto pensado - o ideal, em subjetividade.

A aplicação das categorias de análise na educação dentro dos princípios da unidade de opostos, dadas pelo materialismo histórico-dialético busca ir além da simples análise pela análise. Se almeja construir indícios e elementos que possibilitem chegar ao real, abrangendo indagações que, em raso olhar, não seriam compreensíveis num primeiro momento, mas ao serem aprofundadas, chega-se ao concreto, a essência do fato, que quando circunscrito em uma unidade: um indivíduo, um pequeno grupo, uma instituição, um programa, ou um evento, caracteriza-se um estudo de caso (ALVES-MAZZOTTI, 2006).

Para a implementação do estudo de caso foi escolhida uma unidade escolar do sistema municipal de educação da cidade de Macapá/AP selecionada ao acaso pelos critérios de acessibilidade e/ou conveniência (GIL, 2019). Efetuada a busca ativa pelos contatos com a instituição e devida aproximação com a entidade mantenedora do sistema de ensino ora pesquisado, foi sugerido pelo gestor municipal a participação voluntária dos docentes do recorte solicitado (docentes alfabetizadores). Assim, delimitou-se como sujeitos todos os docentes regentes titulares do $1^{\circ}$ ao $3^{\circ}$ ano do Ensino Fundamental que voluntariamente se dispusessem a participar da pesquisa.

No período de coleta de dados, os docentes receberam um link de acesso ao formulário online por meio de mensagem encaminhada pela 
direção da unidade escolar e assentiu sua participação no Termo de Consentimento Livre e Esclarecido Online que inaugura o formulário. Este instrumento de coleta de dados foi aplicado com suporte na ferramenta Google Formulários ${ }^{\circledR}$, com perguntas objetivas na escala de Likert em 5 itens e complementado com espaço livre de respostas/comentários de forma discursiva.

Essa opção metodológica quedou-se interessante, pois quando cada questão objetiva é completada com uma questão discursiva aberta, o pesquisador consegue não perder o pensamento livre e a originalidade do respondente, sendo possível de surgir respostas das mais variadas, mais representativas e mais fiéis da opinião do inquirido que pode, eventualmente, não ter sido plenamente contemplado em nenhuma das alternativas propostas na escala (DESHAIES, 1992).

$\mathrm{Na}$ análise inicial dos dados coletados, os resultados quantitativos são tabulados e confrontados com as categorias levantadas no todo pelos respondentes a partir de suas respostas discursivas. Para Mingoti (2005), as técnicas de agrupamentos podem ser hierárquicas ou não, sendo as primeiras, em geral, "utilizadas em análises exploratórias dos dados com o intuito de identificar possíveis agrupamentos" (MINGOTI, 2005).

A análise dos dados tabulados e organizados após filtração adequada é feita por meio de análise de conteúdo que é balizado por duas fronteiras: de um lado a fronteira da linguística tradicional e do outro o território da interpretação do sentido das palavras (hermenêutica) e assim sendo, parte de sua definição original (uma técnica de pesquisa que visa uma descrição do conteúdo manifesto de comunicação de maneira objetiva, sistemática e quantitativa) para sua definição mais recente que é de um estudo tanto dos conteúdos nas figuras de linguagem, reticências, entrelinhas, quanto dos manifestos (RODRIGUES; LEOPARDI, 1999). Para Bardin (2011, p. 47), o termo análise de conteúdo designa:

um conjunto de técnicas de análise das comunicações visando a obter, por procedimentos sistemáticos e objetivos de descrição do conteúdo das mensagens, indicadores (quantitativos ou não) que 
permitam a inferência de conhecimentos relativos às condições de produção/recepção (variáveis inferidas) destas mensagens.

Iniciado o processo de aproximação com os docentes da escola campo, sempre foi deixado claro que as potenciais implicações da migração compulsória do ensino presencial para o ensino remoto seriam aferidas na perspectiva dos docentes alfabetizadores, ou seja, aqueles que atuam nos três primeiros anos do ensino fundamental. Essa delimitação de universo, proporcionou o recorte específico da pesquisa em 09 (nove) docentes atuantes no $1^{\circ}$ ao $3^{\circ}$ ano do Ensino Fundamental, que equivale ao período de alfabetização, escolhidos por acessibilidade e conveniência.

A problematização contextual das análises considera as implicações do uso das tecnologias nos processos de alfabetização e letramento mediados tecnologicamente no sentido de fomentar à escolarização da classe trabalhadora na sociedade burguesa no cenário excludente de ensino remoto emergencial, mediatizado por ambientes virtuais.

Durante a aplicação do questionário online, os efeitos da migração compulsória das práticas pedagógicas foram se categorizando no estímulo quanti-qualitativo das respostas objetivas/discursivas do instrumento e agrupados em categorias de análise para serem avaliados por meio de técnicas de análise de conteúdo, a partir de Bardin (2011) para a construção dos significados e encontro das respostas necessárias.

No início do instrumento, ao serem indagados sobre como se sentiram ao receber a determinação para ministrar as suas aulas remotamente, em substituição ao projeto de educação presencial, os respondentes se mostraram indiferentes a ligeiramente frustrados $(66,66 \%)$, conforme se observa nos excertos a seguir:

Quadro 01 - Sentimentos quanto a decisão de migração para o ensino remoto

\begin{tabular}{|l|l|}
\hline Docente 01 & $\begin{array}{l}\text { Fiquei receoso sobre como trabalhar e como essas aulas alcançariam } \\
\text { meus alunos. }\end{array}$ \\
\hline Docente 04 & $\begin{array}{l}\text { Nada a declarar. Só executei a ordem. } \\
\text { Docente 07 }\end{array}$ \\
$\begin{array}{l}\text { Sentimento de frustração, pois já sabia que o ensino remoto não daria } \\
\text { resultado positivo porque a realidade da educação não só do município } \\
\text { de Macapá, mas do Estado em geral, não nos permitiu ter um alcance }\end{array}$ \\
\hline
\end{tabular}

Revista Exitus, Santarém/PA, Vol. 11, p. 01 - 25, e022008, 2022. 


\section{favorável dos alunos.}

Fonte: Questionário Online - Autoria Própria.

O alcance que se refere o docente 07, precisa ser observado à luz dos pressupostos da organização social atual, imersa na lógica do digital, da rede hipertextual, situada no ciberespaço de forma ubíqua, tendo em vista que os dispositivos móveis têm alta mobilidade e são pervasivos, possibilitando o acesso ao ciberespaço na palma da nossa mão. A comunicação agora é fluida - líquida, imediatista, veloz, volátil, ininterrupta, nos levando cada vez mais para uma vida onlife. Uma sociedade híbrida e algorítmica, que dilui a oposição entre off e online, utilizando o imenso volume de dados produzidos diariamente no mundo virtual para delinear interações nas redes sociais e na web, como um todo (MEDEIROS, 2020).

A medida em que a tecnologia adentra no contexto educacional, seja de maneira emergencial como no caso do ensino remoto, ou com o natural desenvolvimento de processos de tecnologias digitais de informação e comunicação aplicáveis a educação, em descompasso com a formação inicial e continuada dos docentes da linha de frente, ocorre o processo de culpabilização e responsabilização, os docentes também são comumente apontados como culpados e responsáveis pelo fracasso no uso de tecnologias dentro da escola. Sua imperícia é muitas vezes apontada como o principal motivo para a não utilização das TDIC's como uma prática pedagógica facilitadora da aprendizagem. Essas análises em alguns casos desconsideram esse processo de desqualificação profissional a que os professores estão submetidos.

Assim, entender o sentimento dos docentes envolvidos na linha de frente e o respectivo receio de falhar no trabalho nessas aulas (remotas) que o docente 01 manifestou, deve ser observado em conjunto aos resultados aferidos quando os respondentes foram indagados se receberam algum tipo de treinamento/formação/orientação para atuar com o ensino remoto, verificou-se que $66,66 \%$ dos respondentes declararam não ter recebido nenhuma ação nesta direção, porém já tinham alguma formação anterior 
para a docência online, e em sua autoavaliação formativa, temos o Quadro 02:

Quadro 02 - Autoavaliação da própria formação para o ensino remoto

\begin{tabular}{|l|l|}
\hline Docente 02 & $\begin{array}{l}\text { Apesar de fazer bom uso dos conhecimentos de informática, eu não } \\
\text { conhecia o meet e nem o classeroom, que estão sendo os dois recursos } \\
\text { digitais mais utilizados nas aulas remotas do município. }\end{array}$ \\
\hline Docente 04 & Nada a declarar. \\
\hline Docente 05 & $\begin{array}{l}\text { Tenho facilidade de manusear e trabalhar com meios tecnológicos, logo } \\
\text { não apresentei dificuldades. }\end{array}$ \\
\hline
\end{tabular}

Fonte: Questionário Online - Autoria Própria.

Questionados sobre os aplicativos e sistemas que fazem uso para 0 exercício de suas atividades em ambientes remotos, 66,66\% declararam estar apenas confortáveis, mas sem segurança de estarem fazendo a coisa certa. Daqueles que quiseram se aprofundar na questão, confirmaram a utilização dos sistemas institucionais para registro e controle das atividades, porém deram um destaque grande ao aplicativo WhatsApp® como canal elementar de comunicação e o Google Meetß para as conferências síncronas, que usam numa forma de ensino presencial teletransmitido, remontando alguns primórdios da educação a distância analógica, com as aulas ministradas ao vivo por sinal enviado via satélite.

O questionamento sobre os sistemas usados é o gancho necessário para discorrer sobre a interação em ambientes remotos, mediados por tecnologias. Aqui se observa um elemento preocupante, pois mesmo os docentes investindo em interações síncronas, majoritariamente realizadas pelo Google Meetß e deixando as atividades interativas e com vídeos instrucionais previamente gravados, $66,66 \%$ dos respondentes declararam terem percebido que os alunos estão pouco motivados durante o processo de interação em ambiente virtual.

Nessa linha de diálogo, muitos recorreram a utilização de material concreto consolidado em caderno de atividades elaborados exclusivamente para cada um dos alunos, conforme suas necessidades, ou a resolução expositiva e demonstrativa de atividades dos livros didáticos, livros do PAAP, e apostilas, complementares àquelas realizadas em ambiente 
virtual, consideradas por $66,66 \%$ dos respondentes como pouco adequadas e pouco eficazes.

No momento seguinte da interação com os docentes, questionou-se sobre as principais dificuldades encontradas com relação ao acesso a plataforma/aplicativo/sistema utilizado para o ensino remoto e suas implicações no processo educativo. A esse estímulo, as principais respostas obtidas foram concatenadas no Quadro 03, abaixo:

Quadro 03 - Principais dificuldades encontradas no ensino remoto

\begin{tabular}{|l|l|}
\hline Docente 03 & $\begin{array}{l}\text { As dificuldades em relação ao acesso a plataforma surgiram mais no início } \\
\text { das aulas remotas, pois nem eu e nem os alunos sabiam fazer bom uso } \\
\text { dessas plataformas disponíveis. }\end{array}$ \\
\hline Docente 05 & $\begin{array}{l}\text { A internet no estado do Amapá é muito ruim. } \\
\text { Docente 07 }\end{array}$ \\
$\begin{array}{l}\text { Por trabalhar em uma área periférica, grande parte dos responsáveis e } \\
\text { alunos não possuem acesso à internet, outros nem aparelho celular tem. } \\
\text { Por conta disso, muitos não deram e não dão retorno das atividades } \\
\text { enviadas. }\end{array}$ \\
\hline
\end{tabular}

Fonte: Questionário Online - Autoria Própria.

Percebe-se nitidamente a partir deste ponto, que uso de tecnologias para os processos de letramento e alfabetização quedaram-se inadequados, em decorrência da imposição do cenário pandêmico que impede a presença física, forçando os processos a adotarem um regime remoto de aprendizagem (mediado ou não em ambientes virtuais.

A acepção conceitual de ensino remoto se aproxima mais da conceituação de educação híbrida do que de ensino presencial. Entender as particularidades de cada conceito na montagem de uma proposta pedagógica disruptiva, que altera o tradicional padrão da aula expositiva e estimula os aspectos criativos do discente, faz com que o docente assuma a função de mediação no ambiente virtual de aprendizagem e integração quando da ação presencial, efetivando a práxis pedagógica completa de conhecimento, a experiência e a interação, fazendo uso de metodologias ativas em sala de aula, de modo a personalizar o ensino, adequando-o a necessidade dos seus alunos. 
Contudo, limitações tecnológicas e sociogeográficas, como apontadas pelos respondentes, agravada pelo cenário pandêmico, é claro, distanciam ainda mais do que se espera da interpolação entre tecnologia educacional e alfabetização. Vejamos no Plano Nacional de Educação, quando na meta 5, de alfabetizar todas as crianças, no máximo, até o final do $3^{\circ}$ (terceiro) ano do ensino fundamental, uma abordagem mais específica, onde o legislador assentiu nas estratégias abaixo que para $\circ$ alcance da meta, os sistemas devem:

5.3) selecionar, certificar e divulgar tecnologias educacionais para a alfabetização de crianças, assegurada a diversidade de métodos e propostas pedagógicas, bem como o acompanhamento dos resultados nos sistemas de ensino em que forem aplicadas, devendo ser disponibilizadas, preferencialmente, como recursos educacionais abertos;

5.4) fomentar o desenvolvimento de tecnologias educacionais e de práticas pedagógicas inovadoras que assegurem a alfabetização e favoreçam a melhoria do fluxo escolar e a aprendizagem dos (as) alunos (as), consideradas as diversas abordagens metodológicas e sua efetividade (BRASIL, 2014, p. 7).

Dois conceitos importantes foram trazidos à baila e merecem destaque para engrandecer a discussão, o primeiro trata dos repositórios chamados de REAs - Recursos Educacionais Abertos, que tem vinculação direta com a acepção de Educação Aberta, conhecimento livre e acessível a todos, transpondo o principal entrave referente aos custos derivados da aplicação dos direitos autorais dos materiais educacionais usados pelos docentes e disponibilizados para os alunos. Segundo Santos (2013, p.21), são "[...] recursos de ensino, aprendizagem e pesquisa que estejam em domínio público, ou que tenham sido disponibilizados com uma licença de propriedade intelectual que permita seu uso e adaptação por terceiros".

O segundo conceito que merece destaque neste trecho é o de Práticas Pedagógicas Inovadoras, que contemplam as inovações nas formas de ensinar e aprender com TDIC e suas múltiplas possibilidades e, a partir desta mudança, incentivar a integração e a convergência entre as modalidades presencial e a distância, com vistas a favorecer a 
institucionalização de métodos e práticas de ensino e aprendizagem inovadores (VIDAL, 2015).

Esse segundo conceito, esbarra na mesma problemática que afastou desta proposta de pesquisa a questão da acepção de novo, pois o que é uma inovação para determinados alunos, pode ser uma prática já conhecida para outros e não ter o mesmo efeito da aplicação original testada no cenário anteriormente experienciado, por isso cabe a nova reflexão.

Se, para $66,66 \%$ dos respondentes, o acesso à tecnologia empregada é a principal causa de insucesso do processo educacional executado remotamente, a frequente inadequação do retorno discente nas respostas dos alunos as atividades propostas, está sendo enfrentada pelos respondentes por meio de estratégias alternativas para reverter os entraves no processo de aprendizagem, sobretudo no período de alfabetização, onde este é mais delicado. Vejamos no Quadro 04 alguns excertos sobre:

Quadro 04 - Avaliação do retorno dado pelos alunos às atividades propostas

\begin{tabular}{|l|l|}
\hline Docente 06 & $\begin{array}{l}\text { As respostas vem muito erradas pois eles não podem tirar dúvidas, bem } \\
\text { como a falta de auxilio dos responsáveis na hora da execução das } \\
\text { atividades. }\end{array}$ \\
\hline Docente 08 & $\begin{array}{l}\text { É inadequado e insuficiente, porque muitos não tem acesso a internet } \\
\text { descente. }\end{array}$ \\
\hline Docente 09 & $\begin{array}{l}\text { A pouca participação, interesse e interação com as tarefas que } \\
\text { precisavam ser desenvolvidas. }\end{array}$ \\
\hline
\end{tabular}

Fonte: Questionário Online - Autoria Própria.

Por fim, diante do que se materializa como mais um ano trabalhando de forma remota e, em alguns casos, trabalhando na perspectiva do ensino híbrido - parte presencial (em grupos pequenos) e parte a distância (ou com atividades remotas ou mediadas por tecnologia), foi indagado aos docentes quais as estratégias de abordagem são utilizadas com seus alunos que não acessam o sistema/aplicativo ou fazem as atividades a contento. As respostas obtidas se concentraram na produção de apostilas específicas impressas para os pais buscarem na escola, bem como ligações, mensagem 
e videochamadas via WhatsApp $\AA$, que se concretiza no principal ponto de contato entre professores/escola e alunos/família.

Hoje, o mensageiro instantâneo WhatsApp $\AA^{5}$ é o aplicativo com maior penetração em todas as camadas sociais brasileiras, promovendo a comunicação de mais de dois bilhões de pessoas, em mais de 180 países, sendo mais de 120 milhões do Brasil, o que implica afirmar que mais da metade da população brasileira é atingida pelo app, o que em muitos casos e cenários, viabiliza m-learning e u-learning, confirmada a consolidação do uso do celular por parte da sociedade brasileira, possibilitou o fortalecimento das pesquisas com aprendizagem móvel e ubíqua, bem explorada por Saccol et al. (2011) com suas respectivas práticas pedagógicas e ferramentas, para o debate dos limites e possibilidades de aplicação conforme o cenário educacional.

Encaminhando-se para o final da coleta de dados, foi indagado aos docentes como é realizada a avaliação, o registro de frequência e o lançamento de conteúdos ministrados e demais itens da documentação pedagógica, e as principais respostas tabuladas no Quadro 05, a seguir:

Quadro 05 - Registros de avaliação, frequência, conteúdos e demais itens da documentação pedagógica

\begin{tabular}{|l|l|}
\hline Docente 02 & $\begin{array}{l}\text { É realizada através do diário online, mas de forma inadequada, pois } \\
\text { faltam campos para informações específicas. }\end{array}$ \\
\hline Docente 05 & $\begin{array}{l}\text { A avaliação de formar diagnóstica, continua e processual. Todos os } \\
\text { conteúdos, atividades e demais itens são lançados no sistema Proesc. }\end{array}$ \\
\hline Docente 06 & $\begin{array}{l}\text { A avaliação e feita mediante participação dos alunos nas atividades. A } \\
\text { frequência, nos foi orientado que nenhum professor poderia e não pode } \\
\text { lançar faltas nos alunos, mesmo não dando retorno das atividades. }\end{array}$ \\
\hline
\end{tabular}

Fonte: Questionário Online - Autoria Própria.

\section{CONSIDERAÇÕES FINAIS}

Seja presencial ou virtualizada, a educação, enquanto processo formativo, exercita a capacidade humana de aprendizagem e desenvolvimento de forma significativa ao levar em conta a realidade social na qual o aprendente está inscrito, suas perspectivas pessoais e profissionais,

\footnotetext{
5 Ver https://wwwl.folha.vol.com.br/tec/2018/07/facebook-chega-a-127-milhoes-deusuarios-mensais-no-brasil.html
} 
bem como as perspectivas dos outros, e deve acontecer de forma emancipadora, a partir de uma relação colaborativa e flexível, que tanto presencialmente quanto virtualmente, não seja excludente.

No cenário observado, mais do que apenas ensinar a manipulação de tecnologia, a mudança de postura deve ter foco voltado a proporcionar aos alunos conhecimentos úteis, de enfrentamento à precarização do processo pedagógico para possibilitar a autonomia crítica dos discentes, posto que parte do objetivo de trazer a tecnologia como ferramenta de desenvolvimento pedagógico no processo de ensino-aprendizagem, de modo a direcionar o estudante a aprender a utilizar tais ferramentas de maneira significativa, reflexiva e ética, no respectivo processo de escolarização da classe trabalhadora dentro de uma sociedade burguesa.

No sistema municipal de ensino de Macapá/AP, na mudança ocorrida por força do cenário pandêmico e por normativas superiores, se observou que implicações da migração compulsória do ensino presencial para o ensino remoto aconteceu de maneira abrupta e com resultados insatisfatórios, na perspectiva de docentes alfabetizadores de uma unidade escolar do município de Macapá.

Observou-se que na tentativa de dar continuidade ao processo educacional, os docentes alfabetizadores, público-alvo desta investigação, demonstraram que a migração para o ensino remoto em decorrência do contexto pandêmico na escola macapaense pesquisada apresentaram, em vários níveis, certa inviabilidade na transposição de práticas pedagógicas com o uso de tecnologias diante da complexidade que envolve os processos de alfabetização e letramento nos três primeiros anos do ensino fundamental no contexto de desigualdades que o sistema está imerso.

Não se mostra viável executar educação remota mediatizada por tecnologia quando grande parte dos responsáveis e alunos não possuem acesso à internet, outros nem aparelho celular tem, fazendo com que a alfabetização, etapa importante da escolarização, reste prejudicada. Os sistemas como um todo devem rever posição e realinhar processos. 
Por fim, ao constatar estas dificuldades, parece óbvio que devem ser adotadas medidas de redimensionamento do processo educacional de alfabetização do momento inicial do ensino fundamental, base da escolarização discente, no sentido de fomentar a capacitação específica para adequada transposição didática aos processos pedagógicos online por parte dos docentes e a universalização tecnológica para todos os discentes, contemplando recursos de acessibilidade específicos ao nível de ensino e, tais processos, ensejam alto investimento e interesse por parte do sistema mantenedor e, deve contemplar a participação dos diferentes atores educacionais para que o processo seja significativo.

\section{REFERÊNCIAS}

ALVES-MAZZOTTI, A. J. O método nas ciências naturais e sociais: pesquisa quantitativa e qualitativa. São Paulo: Pioneira, 2006.

BARDIN. L. Análise de conteúdo. SP: Edições 70, 2011.

BRASIL. Lei no 13.005, de 25 de junho de 2014. Aprova o Plano Nacional de Educação - PNE e dá outras providências. Diário Oficial da União, Brasília, DF, 26 jun. 2014. Disponível em: <http://www.planalto.gov.br/ccivil_03/_A†o20112014/2014/Lei/L13005.htm >. Acesso em: 20 jul. 2021.

CORRADINI, S. N.; MIZUKAMI, M. da G. N. Práticas pedagógicas e o uso da informática. Revista Exitus, [S. I.], v. 3, n. 2, p. 85-92, 2016. Disponível em: http://www.ufopa.edu.br/portaldeperiodicos/index.php/revistaexitus/article/view/15 2. Acesso em: 20 jul. 2021.

CULLINANE, C.; MONTACUTE, R. COVID-19 and Social Mobility Impact Brief \# 1:

School closures. Disponível em: <https://www.suttontrust.com/wpcontent/uploads/2021/01/School-Shutdown-Covid-19.pdf>. Acesso em: 4 jan. 2021.

DESHAIES, B. Metodologia da investigação em ciências humanas. Lisboa: Instituto Piaget, 1992.

FREIRE, P. A importância do ato de ler. 31ª ed. São Paulo: Cortez,1995.

FREIRE, P. Pedagogia da autonomia: saberes necessários à prática educativa. $25^{\mathrm{a}}$ ed. São Paulo: Paz e Terra, 1996.

GIL, A. C. Métodos e técnicas de pesquisa social. $7^{a}$ ed. São Paulo: Atlas, 2019.

LUCON, J. S.; ZIBETTI, M. L. T. Alfabetização de crianças: concepções e perspectivas. Revista Exitus, [S. I.] v. 10, n. 1, p. e020032, 2020. DOI: 10.24065/22379460.2020v10n0ID1256. Disponível em: 
<http://www.ufopa.edu.br/portaldeperiodicos/index.php/revistaexitus/article/view/ 1256>. Acesso em: 22 jul. 2021.

MEDEIROS, R. de A. Ser docente universitário em tempos digitais: (trans)formar é preciso. 2020. 280 f. Tese (Doutorado em Educação). Faculdade de Educação, Universidade de São Paulo, 2020.

MINGOTI, S. A. Análises de dados através de métodos de estatística multivariada: uma abordagem aplicada. Belo Horizonte: Editora UFMG, 2005.

RODRIGUES, M. S. P.; LEOPARDI, M. T. O método de análise de conteúdo: uma versão para enfermeiros. Fortaleza (CE): Fundação Cearense de Pesquisa e Cultura, 1999.

SACCOL, A.; SCHLEMMER, E.; BARBOSA, J. M-learning e u-learning: novas perspectivas das aprendizagens móvel e ubíqua. São Paulo: Pearson Prentice Hall, 2011.

SANTOS, A. I. Recursos educacionais abertos no Brasil: o estado da arte, desafios e perspectivas para o desenvolvimento e inovação / [tradução DB Comunicação]. São Paulo: Comitê Gestor da Internet no Brasil, 2013. [livro eletrônico]; PDF; 1,6 Mb. Título original: Open Education Resources in Brazil: state of the art, challenges and prospects for development and innovation. ISBN 978-85-60062-64-5.

SAVIANI, D. Crise estrutural, conjuntura nacional, coronavírus e educação - o desmonte da educação nacional. Revista Exitus, [S. I.], v. 10, n. 1, p. e020063, 2020. DOI: 10.24065/2237-9460.2020v10n1ID1463. Disponível em:

<http://www.ufopa.edu.br/portaldeperiodicos/index.php/revistaexitus/article/view/ 1463>. Acesso em: 22 jul. 2021.

SEMED/PMM. PORTARIA NNo 182/2020 - SEMED/PMM. Disponível em: <https://macapa.ap.gov.br/coronavirus/wp-content/uploads/2020/09/PORTARIA182-2020-SEMED.pdf> Acesso em: 4 jan. 2021.

SOARES, Magda. Letramento em texto didático: o que é letramento e alfabetização. In: Letramento: um tema de três gêneros. Belo Horizonte: Autêntica Editora, 2012.

SHULMAN, L. Knowledge and teaching: Foundations of the new reform. Harv. Educ. Rev., 57, 1-23, 1987.

VIDAL, O. F. Práticas pedagógicas inovadoras: narrativas sobre integração das tecnologias digitais da informação e comunicação no ensino superior. 2015. 204 f.: il. Tese (doutorado em Educação) - Universidade Federal de Alagoas. Centro de Educação. Programa de Pós-Graduação em Educação. Maceió, 2015.

Recebido em: 12 de setembro de 2021. Aprovado em: 20 de dezembro de 2021.

Publicado em: 07 de janeiro de 2022. 